\title{
Association between respirable dust exposure and lung function deterioration among construction site workers
}

\author{
Nur Nabilah Mohamad Sulaiman, Normah Awang* and \\ Nurul Farahana Kamaludin \\ Centre for Toxicology and Health Risk Studies, Faculty of Health Sciences, UKM, Kuala Lumpur, Malaysia
}

\begin{abstract}
Construction workers are at risk of developing respiratory health problems because they are exposed to various forms of dust at the construction site. This study aimed to evaluate the exposure to respirable dust level and respiratory health of construction site workers. Personal Air Sampling Pump was used to determine the exposure to respirable dust. Meanwhile, the spirometry test was performed to assess the efficiency of the lung function. Based on independent T-test, the exposed workers showed significantly higher exposure to respirable dust level than nonexposed workers. The lung function parameters (FVC\%, FEV1\% and FEV1/FVC\%) were lowered significantly among the exposed workers compared to the non-exposed workers. Cough and phlegm have been reported to be the most probable symptoms determined among the construction workers. In conclusion, personal exposure to high level of respirable dust increased the risk of lung function deterioration.
\end{abstract}

Keywords: Construction workers, cross-sectional study, lung function, responsible dust exposure, respiratory health.

CONSTRUCTION is one of the most stable and growing sectors of the world. The risks in the construction sector are eight times more hazardous than those of the manufacturing industry ${ }^{1}$. Construction is considered as one of the intensive vocations of labour, and construction workers carry out high-risk jobs for low wages. Dusty activities such as abrasive blasting, emptying bags of cement, woodcutting and masonry expose these workers to danger. They are subjected to multiple risks at their places of working and living. The workers are vulnerable to physical, chemical, biological, ergonomic and environmental, and psychosocial hazards ${ }^{2}$.

Construction activities produce high amounts of dust, which may contribute to an increased risk of severe respiratory dysfunctions among construction workers ${ }^{3}$. This includes impairment of the lung, coughing, asthma aggravation, chronic bronchitis, and mucus secretion ${ }^{4}$. Such

\footnotetext{
*For correspondence. (e-mail: norm@ukm.edu.my)
}

symptoms arise due to respiratory tract inflammation, causing people to be more vulnerable to respiratory tract infections ${ }^{5}$. The particulate matter in construction dust is mostly PM-10 (particulate matter with diameter less than $10 \mu \mathrm{m})$. Silica is a mineral that is found on the Earth's surface. During chasing or drilling, airborne silica dust is produced from concrete, brickwork, scraping-up old concrete, sandstone or clay excavation sites. The workers at the construction site are exposed to these airborne particles $^{6}$. Impaired lung function is the most prevalent respiratory condition among workers exposed to dust. Construction workers are more exposed to respirable crystalline silica and particulates not otherwise specified (PNOS) relative to the occupational exposure limit. Further studies are needed for monitoring the condition of construction workers ${ }^{6,7}$. According to the International Labour Organisation (ILO), silicosis is a preventable but incurable lung disease. Hence, the education of the quality and quantity of respirable crystalline silica is crucial in order to implement proper control measures ${ }^{8}$.

Based on the National Institute of Occupational Safety and Health (NIOSH) study, the highest mortality rate from silicosis was correlated with construction activities compared to other industries during 1990-1999 (ref. 9). In some of the construction work groups handling materials like concrete, ceramics and bricks, reduction in lung function parameters such as forced expiratory volume/ forced vital capacity (FEV1/FVC), peak expiratory flow rate (PEFR), forced expiratory flow (FEF25-75), FVC and FEV1 due to cumulative exposure to respirable PNOS and silica dust, together with airway obstruction have been recorded ${ }^{10,11}$. There have also been reports of respiratory problems correlated with changes in the chest $\mathrm{X}$-ray and lung function among construction workers ${ }^{12,13}$.

Inhaled and lodged in the lung, dust particles irritate and trigger an aggressive response. Fibrosis is caused by the healing of this inflammation leading to inadequate oxygen intake and reduced lung function ${ }^{14}$. Spirometric parameters can be used in adults to differentiate the obstructive and restrictive lung status. Spirometry is one of the most effective diagnostic techniques for occupational respiratory diseases. It plays an important role in the diagnosis and prognosis of these diseases and describes 


\section{RESEARCH ARTICLES}

the impact of restriction or obstruction on the functioning of the lungs ${ }^{15}$. Regular monitoring of workers enables the diagnosis of pulmonary disease in its early stages, where corrective interventions are more liable to benefit.

There are currently minimal data regarding the prevalence of respiratory symptoms among construction workers in the developing countries. The aim of this study was to evaluate the exposure of construction workers to respirable dust and their respiratory symptoms and lung function status, given the high occupational exposure of these workers to airborne dust and the lack of related studies.

\section{Methodology}

\section{Study design and period}

A cross-sectional study was conducted to assess respiratory symptoms, measure lung function and personal respirable dust exposure among workers from a construction site in Malaysia. It is a phase- 2 construction site of a mall, which is the extension of an existing mall comprising three levels of retail floor (level LG, level UG and level 1) and one level of open car park (level 2). The project involves a large number of employees. The period of study was from April 2019 to January 2020.

\section{Study population and sample size}

The sample size required for this study was calculated using the $\mathrm{G}^{*}$ Power software (version 3.1.9.2) based on mean difference of samples by taking into consideration the percentage of forced expiratory volume in one second (FEV1) to forced vital capacity (FVC) as the primary output with $95 \%$ power, $95 \%$ confidence interval and $5 \%$ significance level. The percentage of FEV1/FVC for the exposed $(95.33, \mathrm{SD}=6.86)$ and control $(99.8, \mathrm{SD}=1.43)$ groups was taken from previous studies conducted among construction industry workers in India. Based on the $\mathrm{G}^{*}$ Power software, the estimated number of subjects required was 68, i.e. 34 exposed workers and 34 nonexposed workers. In this study, the sample was 70 , with 35 workers from the exposed group and 35 from the nonexposed group. The random sampling method based on exposure during working was used in this study.

The exposed group consisted of those who worked with high and direct exposure to respirable dust at the construction site. Whereas the non-exposed group comprised of administrative staff who worked in the office with less and indirect exposure to respirable dust. The list of workers names was obtained from the Department of Human Resource, Management of Construction site. The selection of the two groups was based on the inclusion criteria of male workers aged between 18 and 55 years, who had worked in the construction site for six or more months and without any medical history or under any treatment for respiratory diseases.

\section{Data collection}

The construction site was visited before the study was commenced. After obtaining permission to conduct the study, the list of employees in the construction site was acquired from the management as the first step of data collection. The walk-through survey was done to evaluate the workers' awareness, attitudes and practices concerning chemical hazards and personal protective devices. Prior to the actual data collection, randomly selected workers were briefed about the goals of the study, its significance, and how the interview and lung function assessments were administered, along with the written consent to participate in the study.

\section{Exposure measurement}

The list of all construction workers and administrative staff was used to select workers for dust sampling randomly. A personal air sampling pump (Gilian GilAir-3) was placed at the workers' breathing zone area and used to determine the personal exposure level to respirable dust in $8 \mathrm{~h}$. In this sampling, personal exposure of the workers to respirable dust was calculated according to the NIOSH Method No. 0600. Each sampling pump was calibrated at a set flow rate based on cyclone type, i.e. $1.7 \mathrm{l} / \mathrm{min}$ for nylon cyclone type. This cyclone is designed to separate a small portion of the air dust from inhaled fragments. Polyvinyl chloride (PVC) filters (USA) with $37 \mathrm{~mm}$ diameter and $5 \mu \mathrm{m}$ pore size were placed in a closed-faced cassette. The sampling began after the workers were briefed about the study.

Daily activities and relevant situations were recorded during the sampling. The ideal sampling period for a working day was $8 \mathrm{~h}$. However, in this study, the sampling duration varied depending on the weather condition, and was between 6 and $8 \mathrm{~h}$. Therefore, each sample was adjusted on a standard $8 \mathrm{~h}$ working day. The filters were weighed after the sampling and drying processes, using a balance (Sartorius MC balance) at $0.01 \mathrm{mg}$ resolution. A threshold limit value (TLV) of $10 \mathrm{mg} / \mathrm{m}^{3}$ was used for respirable PNOS as the occupational exposure limit, according to the American Conference of Governmental Industrial Hygienists.

\section{Respiratory symptoms assessment}

The workers were assisted in answering the questionnaire. Information on respiratory symptoms was collected using an established questionnaire adapted from the American Thoracic Society (ATS). The pilot study was 
conducted at another construction site, with $20 \%$ of the actual sample size, and high values of Cronbach's alpha coefficient above 0.7 for the symptoms. Information was collected on gender, age (years), number of years working in the current industry, employment history in a dusty work environment, and smoking status. Questions about the history of respiratory diseases experienced by the workers were also included. They had to state if they ever had any respiratory illness.

Questions about respiratory symptoms were as follows: Did the workers experience cough, cough with phlegm, phlegm, cough and phlegm, wheezing, chest tightness and shortness of breath during the past 12 months?

\section{Lung function test}

Workers from the exposed and non-exposed groups who passed the inclusion criteria had to undergo lung function test (COSMED Pony FX Spirometer) (Rome, Italy), as suggested by the ATS. The characteristics of the exposed and non-exposed groups, such as height, weight, age and smoking status were recorded. The lung function tests were done after gathering information on comprehensive history and collecting anthropometric data. Spirometry is one of the techniques used to measure airflow obstruction in the lungs. The readings on the spirometer were FVC, FEV1, and \%FEV1/FVC (forced expiratory ratio). The pulmonary status was defined as restrictive or obstructive, and the findings were interpreted following the guidelines of the ATS.

\section{Data analysis}

The data obtained in the study were analysed using Statistical Package for Social Sciences (SPSS) version 21 (IBM Corp., NY, USA). A probability value of 0.05 or less was used as the criterion for statistical significance. Independent $t$-test was used for comparison of the spirometric readings (FEV1, FVC and \%FEV1/FVC) between the exposed and non-exposed groups of workers at the construction site. Other tests such as the Pearson correlation, chi-square and logistic regression were used for statistical analysis in this study.

\section{Ethical approval}

The ethical approval for this study was obtained from the Research and Ethics Committee, Universiti Kebangsaan Malaysia (UKM) Medical Centre, Malaysia (UKM reference number PPI/111/8/JEP-2019-052 dated 15 February 2019). All data were kept confidential throughout the study. The procedure of the study was explicated to the workers, and their willingness to participate was confirmed by their signatures on the consent form before data collection. The outcomes of the questionnaire and spirometry assessment were recorded only with the ID numbers of the participants and not their names.

\section{Results}

\section{Sociodemographic data}

The randomly selected workers had given their consent before the sampling was done. Table 1 summarizes the findings of the sociodemographic data of the workers in this study. All the workers who participated in this study were male. The mean age of the workers in the exposed group was $33.97 \pm 9.41$ years, while in the non-exposed workers it was $34.40 \pm 12.39$ years. The weight and height of the exposed group was $68.26 \pm 8.24 \mathrm{~kg}$ and $166.52 \pm 3.90 \mathrm{~cm}$ respectively. Whereas the weight and height of the non-exposed group was $74.514 \pm 7.33 \mathrm{~kg}$ and $168.51 \pm 5.53 \mathrm{~cm}$ respectively. The mean working experience in the construction industry for the exposed group was $8.74 \pm 3.50$ years, and non-exposed group was $10.37 \pm 3.90$ years. To compare the exposed and nonexposed groups, data were analysed using independent $t$-test. No significant differences were noted in age, weight, height and working period between both groups, as shown by a $P$-value of more than 0.05 .

\section{Personal exposure level (respirable dust)}

A total of 70 respirable dust samples were collected from both exposed and non-exposed groups, i.e. 35 samples were taken in order to represent each group of workers. Monitoring of the workers' exposure level was done during their working hours. Independent $t$-test was conducted to compare the exposure level between both groups. The results in Table 2 indicate a significant

Table 1. Sociodemographic data of exposed and non-exposed groups

\begin{tabular}{lrrr}
\hline Parameters & $\begin{array}{c}\text { Exposed } \\
(\text { mean } \pm \mathrm{SD})\end{array}$ & $\begin{array}{c}\text { Non-exposed } \\
(\text { mean } \pm \mathrm{SD})\end{array}$ & $P$-value \\
\hline Age $(\mathrm{yrs})$ & $33.97 \pm 9.41$ & $34.40 \pm 12.39$ & 0.871 \\
Weight $(\mathrm{kg})$ & $68.26 \pm 8.24$ & $74.514 \pm 7.33$ & 0.060 \\
Height $(\mathrm{cm})$ & $166.52 \pm 3.90$ & $168.51 \pm 5.53$ & 0.086 \\
Working period (yrs) & $8.74 \pm 3.50$ & $10.37 \pm 3.90$ & 0.350 \\
\hline
\end{tabular}

Table 2. Level of respirable dust of exposed and non-exposed groups

\begin{tabular}{lcc}
\hline Parameters & Exposed $(N=35)$ & Non-exposed $(N=35)$ \\
\hline $\begin{array}{l}\text { Mean (SD) } \\
P \text {-value }\end{array}$ & $2.38(0.86)$ & $0.45(0.23)$ \\
$\begin{array}{l}\text { No. of subjects } \\
\text { exceeded limit (\%) }\end{array}$ & $9(25.7)$ & 0 \\
$\begin{array}{l}\text { No. of subjects not } \\
\text { exceeded limit }(\%)\end{array}$ & $26(74.3)$ & $35(100)$ \\
\hline
\end{tabular}




\section{RESEARCH ARTICLES}

difference in the exposure level of respirable dust between the exposed and non-exposed groups $(P<0.001)$. The permissible exposure limit for respirable dust under the Occupational Safety and Health (Use and Standard of Exposure to Chemical Hazardous to Health) Regulations 2000 in the Malaysia Occupational Safety and Health Act 1994 (Act 514) or ACGIH is $3 \mathrm{mg} / \mathrm{m}^{3}$ in $8 \mathrm{~h}$ timeweighted average airborne concentration. Approximately $25.7 \%$ of the exposed group exceeded the permissible exposure limits. However, all workers from the nonexposed group did not exceed the permissible exposure limit.

\section{Prevalence of respiratory health symptoms}

Table 3 shows the percentage of workers from the exposed and non-exposed groups who experienced respiratory symptoms. The four main symptoms denoted as early signs of lung-related diseases are cough, shortness of breath, phlegm and wheezing. Overall, the exposed group experienced higher respiratory symptoms than the non-exposed group.

The exposed group exhibited the highest percentage of cough symptoms, i.e. $68.6(n=24)$, while only $25.7 \%$ $(n=9)$ of the workers from the non-exposed group showed similar symptoms. About $37.1 \%(n=13)$ of the exposed group had symptoms of shortness of breath, while only $17.1 \%(n=6)$ of the non-exposed group experienced it. The least percentage of workers from both groups experienced symptoms of wheezing, with only $17.1 \%(n=6)$ in the exposed group and $11.4 \%(n=4)$ in the non-exposed group. Hence, the results obtained show that the exposed group of workers mostly experience cough, followed by phlegm, shortness of breath and wheezing.

However, only cough and phlegm were found to show a significantly positive relationship between the exposed and non-exposed group of workers with $\mathrm{PR}=5.321$ for

Table 3. Respiratory symptoms among exposed and non-exposed groups

\begin{tabular}{|c|c|c|c|c|}
\hline Symptoms & $\begin{array}{c}\text { Exposed } \\
n(\%)\end{array}$ & $\begin{array}{c}\text { Non-exposed } \\
n(\%)\end{array}$ & $P$-value & $\begin{array}{c}\text { Prevalence } \\
\text { ratio } 95 \% \\
\text { CI }\end{array}$ \\
\hline \multicolumn{5}{|l|}{ Cough } \\
\hline Yes & $24(68.6)$ & $9(25.7)$ & 0.003 & 5.321 \\
\hline No & $11(31.4)$ & $26(74.3)$ & & \\
\hline \multicolumn{5}{|l|}{ Phlegm } \\
\hline Yes & $18(51.4)$ & $9(25.7)$ & 0.040 & 3.297 \\
\hline No & $17(48.6)$ & $26(74.3)$ & & \\
\hline \multicolumn{5}{|l|}{ Wheezing } \\
\hline Yes & $6(17.1)$ & $4(11.4)$ & 0.174 & 2.477 \\
\hline No & $29(82.9)$ & $31(88.6)$ & & \\
\hline \multicolumn{5}{|c|}{ Shortness of breath } \\
\hline Yes & $13(37.1)$ & $6(17.1)$ & 0.781 & 0.797 \\
\hline No & $22(62.9)$ & $29(82.9)$ & & \\
\hline
\end{tabular}

cough and $\mathrm{PR}=3.297$ for phlegm. Thus, exposed workers had 5.3 times higher risk of getting cough and 3.3 times of getting phlegm than the non-exposed workers.

\section{Comparison of lung function test}

Table 4 shows a comparison of mean and standard deviation of lung function test parameters for the exposed and non-exposed group of workers. Based on the results of the lung function test, all parameters tested showed differences between the two groups. Overall, the value of each parameter obtained for the exposed group was lower than the non-exposed group.

Reported mean readings and standard deviations for the exposed group were FVC: $70.40 \pm 12.27$, FEV1: $72.20 \pm 11.35$ and FEV1/FVC\%: $93.60 \pm 11.79$. For the non-exposed group, they were FVC: $84.40 \pm 13.33$, FEV1: $82.29 \pm 12.53$ and FEV1/FVC\%: $100.63 \pm 9.33$. Based on the independent $t$-test, significant differences were observed for FVC, FEV1 and FEV1/FVC. The significant $P$-value was $<0.05$. The $P$-value for $\mathrm{FVC}$ was $<0.001$, for FEV1 it was 0.001 and for FEV1/FVC it was 0.007 . Thus, the lung function of the exposed group of workers was significantly lower than that of the nonexposed group.

The results of the lung function test were divided into two groups, namely normal and abnormal. Both obstructive and restrictive status were classified as abnormal. We found that about $80 \%(n=28)$ of the exposed group and $40 \%(n=14)$ of the non-exposed group had abnormal lung function. The lung abnormalities were identified by FVC $\%$ and FEV1\%. The restrictive condition emerged when $\mathrm{FVC} \%$ and $\mathrm{FEV} 1 \%$ decreased to $<80 \%$ and $\mathrm{FEV} 1 /$ $\mathrm{FVC} \%$ was $>70 \%$. Meanwhile, obstructive disorder occurred when FEV1\% decreased to less than $80 \%$ and FVC $\%$ to less than $80 \%$, while FEV1/FVC $\%$ decreased to $<70 \%$. The group of exposed workers had a higher likelihood of lower lung function as a result of direct exposure to dust particles compared to the non-exposed group, which was indirectly exposed.

The chi-square test was performed to determine the relationship between respiratory symptoms and normality of lung function (Table 5). In this study, only cough symptoms had a significant relationship with normality of lung function $\left(P=0.002, \chi^{2}=9.182\right)$. Symptoms of

Table 4. Lung function of exposed and non-exposed groups

\begin{tabular}{lccc}
\hline & $\begin{array}{c}\text { Exposed } \\
N=35\end{array}$ & $\begin{array}{c}\text { Non-exposed } \\
N=35\end{array}$ & \\
Parameters & $($ mean $\pm \mathrm{SD})$ & $($ mean $\pm \mathrm{SD})$ & $P$-value \\
\hline FVC\% & $70.40 \pm 12.27$ & $84.40 \pm 13.33$ & $<0.001$ \\
FEV1\% & $72.20 \pm 11.35$ & $82.29 \pm 12.53$ & 0.001 \\
FEV1/FVC\% & $93.60 \pm 11.79$ & $100.63 \pm 9.33$ & 0.007 \\
\hline FVC, Forced vital capacity; FEV1, Forced expiratory volume in one \\
second.
\end{tabular}


RESEARCH ARTICLES

Table 5. Association of respiratory symptoms and lung function of exposed and non-exposed groups

\begin{tabular}{|c|c|c|c|c|c|}
\hline \multirow[b]{2}{*}{ Respiratory symptoms } & \multirow[b]{2}{*}{ Normality of lung function } & \multirow{2}{*}{$\begin{array}{c}\text { No. of workers }(\%) \\
\text { Exposed group }(n=35)\end{array}$} & No. of workers $(\%)$ & \multirow[b]{2}{*}{$\chi^{2}$} & \multirow[b]{2}{*}{$P$-value } \\
\hline & & & Non-exposed group $(n=35)$ & & \\
\hline \multirow[t]{2}{*}{ Cough } & Normal & $2(5.7)$ & $7(20)$ & 9.182 & 0.002 \\
\hline & Abnormal & $22(62.9)$ & $2(5.7)$ & & \\
\hline \multirow[t]{2}{*}{ Phlegm } & Normal & $2(5.7)$ & $6(17.1)$ & 1.970 & 0.124 \\
\hline & Abnormal & $16(45.7)$ & $3(8.6)$ & & \\
\hline \multirow[t]{2}{*}{ Wheezing } & Normal & $1(2.9)$ & $2(5.7)$ & 1.944 & 0.148 \\
\hline & Abnormal & $5(14.3)$ & $2(5.7)$ & & \\
\hline \multirow[t]{2}{*}{ Shortness of breath } & Normal & $1(2.9)$ & $4(11.4)$ & 0.771 & 0.275 \\
\hline & Abnormal & $12(34.3)$ & $2(5.7)$ & & \\
\hline
\end{tabular}

Table 6. Correlation of level of respirable dust and lung function test

\begin{tabular}{|c|c|c|c|c|c|c|}
\hline \multirow[b]{2}{*}{ Correlation } & \multicolumn{3}{|c|}{ Exposed group $(n=35)$} & \multicolumn{3}{|c|}{ Non-exposed group $(n=35)$} \\
\hline & Mean \pm SD & $r$-value & $P$-value & Mean \pm SD & $r$-value & $P$-value \\
\hline \multicolumn{7}{|c|}{ Concentration of respirable dust } \\
\hline $\mathrm{FVC} \%$ & $72.20 \pm 11.35$ & -0.186 & 0.02 & $82.29 \pm 12.53$ & -0.095 & 0.59 \\
\hline FEV1\% & $70.40 \pm 12.27$ & -0.016 & 0.93 & $84.40 \pm 13.33$ & -0.111 & 0.53 \\
\hline FEV1/FVC\% & $93.60 \pm 11.79$ & 0.12 & 0.49 & $100.63 \pm 9.33$ & -0.072 & 0.68 \\
\hline
\end{tabular}

phlegm did not show any significant relationship with normality of lung function, with the value of $P=0.124$, $\chi^{2}=1.97$. Other symptoms such as wheezing and shortness of breath also did not show any significant relationship with the normality of lung function.

\section{Correlation between respirable dust and lung function parameters}

The relationship between respirable dust concentration and lung function test parameters was analysed using the Pearson correlation statistical test (Table 6). The results of this test showed moderate negative relationship between respirable dust concentration and lung function parameters. Based on the tests conducted, only the relationship between concentration of respiration dust and FVC parameter for the exposed group showed a significant relationship, with the value of $P=0.02$. However, the relationships for other parameters did not indicate significant values. In addition, for the non-exposed group, FVC, FEV1 and FEV1/FVC did not show any significant relationship with exposure to respirable dust.

\section{Discussion}

\section{Sociodemographic data}

All workers selected to participate in this study were male, because majority of the workers at the construction site were male. Only a few workers in the non-exposed group were females. The sociodemographic data collected in this study were age, height, weight and working period. According to the ATS, age, weight and height influence lung function and inflammation of the airways $^{16}$. In addition, duration of work can also influence lung function. In this study, age, height and weight of the exposed and non-exposed group of workers did not show any significant difference. Therefore, these factors might not positively influence the spirometry results. These results were similar to those of a previous study, which also reported no significant difference in the anthropometric parameters ${ }^{10}$. Moreover, smokers were excluded from this study. The smoking status of the subjects needs to be controlled, as recommended by several studies. Besides, the working period also did not show any significant difference between the exposed and non-exposed groups. The smoking status and working duration could also affect the respiratory function of the workers ${ }^{16,17}$.

\section{Respirable dust}

Occupational exposure to the calculated $8 \mathrm{~h}$ total weighted average of respirable dust was higher in the exposed group compared to the non-exposed group. The measurement showed a high concentration of respirable dust among the exposed group of construction workers, where the calculated $8 \mathrm{~h}$ TWA exceeded the permissible exposure limit in nine out of $35(25.7 \%)$ workers in the exposed group, while no sample from the non-exposed group exceeded the limit. The statistical analysis shows a significant difference of personal exposure to respirable dust between the construction and administrative workers. Previous studies reported some typical activities of the construction industry, with exposure to the high concentration of respirable dust, especially when using 


\section{RESEARCH ARTICLES}

hand-held tools, such as power saws and angle grinder. Besides, there was a lower but significant exposure to respirable dust concentration in drilling and other work tasks $^{18}$. Tavakol et al. $^{8}$ reported that batching and concrete workers were among those who showed the highest average exposure to respirable dust, attributable to the form of task with the ongoing exposure in operational processes at the site, such as mixing and transfer of sand, gravel and cement.

This indicates that the construction workers were more exposed to respirable dust than staff in the office. In addition, the construction workers were exposed directly to a higher concentration of dust produced from the tasks when working compared to the administrative staff who worked in a closed office equipped with adequate ventilation system. The dust contains cement and silica that could accumulate in the lungs of the workers after prolonged exposure and could cause respiratory diseases ${ }^{19}$. On the contrary, although the level of exposure to respirable dust among the non-exposed group did not exceed the permissible exposure limit, they are also at risk. This is because the office building is located near the construction site where respirable particles are wind-blown and could be trapped inside the office. Besides, the non-exposed group also had to spend some time at the construction site.

\section{Prevalence of respiratory health symptoms}

The symptoms of respiratory health were evaluated using a standardized questionnaire from the ATS. The workers answered questions on sociodemographic, and socioeconomic status, history of respiratory health, diet and working history. The history of respiratory health included history of cough, phlegm, wheezing and chest tightness among the workers.

This study reported that workers from both groups mostly experienced cough and phlegm. The number of cough occurrences among the exposed workers was 24 $(68.6 \%)$ while it was $9(25.7 \%)$ among the non-exposed workers. The number of phlegm occurrences among the exposed workers was $18(51.4 \%)$ and it was $9(25.7 \%)$ among the non-exposed workers. Among all the symptoms, only cough and phlegm had a significant positive association with exposure among the contraction workers.

Previous studies reported that exposure to cement dust also had a significant association with the incidence of $\operatorname{cough}^{17,19}$. Considering that construction workers in this study were also exposed to cement dust, the risk of developing cough could be high. Furthermore, following several previous studies, the present study also recorded higher prevalence rate of several respiratory symptoms among the exposed construction workers compared to the non-exposed workers ${ }^{20-23}$. In this study, only cough and phlegm were reported to have a significantly positive relationship between the exposed and non-exposed group of workers with $\mathrm{PR}=5.321$ for cough and $\mathrm{PR}=3.297$ for phlegm, as reported by Neghaband and Choobineh ${ }^{24}$ and Ahmed and Abdullah ${ }^{25}$. Thus, the exposed workers had 5.3 times higher risk of getting cough and 3.3 times of getting phlegm than those from the non-exposed group. A higher prevalence of respiratory symptoms recorded among the exposed workers could be due to the prolonged exposure to dust during working, resulting in irritation of the respiratory tract that contributes to cough and other respiratory symptoms. Occupational respiratory disorders are typically triggered by prolonged exposure to unpleasant or toxic substances that can cause acute or chronic breathing difficulties ${ }^{26-28}$. The occurrence relies upon the chemical composition of dust, particle size, exposure duration and vulnerability of an individual ${ }^{14,29}$.

\section{Comparison of lung function test}

Due to the lack of data regarding lung function of construction workers globally, we conducted lung function test for the workers. We found that $\mathrm{FVC} \%$, FEV1\%, and FEV1/FVC\% were significantly lower in the exposed group compared to the non-exposed group. In this study, the reduction in the parameters of lung function among exposed group versus non-exposed group was consistent with the results reported in the literature ${ }^{16,28,30,31}$. Nij et $a l .{ }^{6}$ found that obstructive pulmonary status was linked to exposure to crystalline silica in construction workers. Tavakol et al. ${ }^{8}$ reported that more than half of construction workers $(51.8 \%)$ were diagnosed with mild pulmonary restriction, and only $4.70 \%$ were listed as obstructive. Meanwhile, in the present study, $80 \%(n=28)$ of the exposed workers had obstructive and restrictive lung function. The results of these studies support that construction workers are at a risk of developing pulmonary diseases.

\section{Lung function and respiratory symptoms}

Only cough symptom showed significant association with lung function abnormality in this study. This proves that cough is one of the common symptoms in respiratory diseases.

\section{Correlation between age, respirable dust and working duration with lung function levels}

Based on the results, respirable dust exposure showed significant negative relationship with $\mathrm{FVC} \%$ of the exposed workers. This implies that an increased concentration of exposure to respirable dust would result in reduced level of lung function. This outcome indicates that the greater exposure to respirable dust could increase 
the risk of lung deterioration. This result complies with the study by Kamaludin et al. ${ }^{19}$, who evaluated the exposure of respirable dust among cement workers. Extended exposure to high concentrations of respirable dust might reduce $\mathrm{FVC} \%$.

The accumulation of foreign particles such as PM2.5 in the bronchial tree prevents the lungs from exhaling fully by reducing FVC and thereby decreasing the lung function status ${ }^{32}$. However, occupational exposure to air pollutants causes a decline in lung function levels, i.e. the FEV1 predictors ${ }^{33}$. Green et al. ${ }^{34}$ demonstrated the impact of long-term mineral dust exposure among young adults in India, and showed that FVC in this population was significantly lower than the control group. Yang et al. ${ }^{35}$ reported that cement dust caused high prevalence of chronic respiratory diseases and reduced ventilation capacity in the assessment of the relationship between cement dust exposure and ventilation function. The workers were exposed to dust during the process of cutting, sawing, or grinding any building materials at the construction site. Meanwhile, dust emerging from operations like drilling, blasting and grinding became airborne, and particle inhalation could cause accelerated decline of lung function ${ }^{29}$.

\section{Conclusion}

The working environment influences the well-being of workers. Those working in dusty environments face the risk of breathing in particles that may have detrimental effects on their respiratory system. Every construction site produces high dust levels, usually from concrete, silica, asbestos, cement, wood, stone, sand, etc.

Lung dysfunction typically depends on direct or indirect exposure to particles of dust. However, other characteristics, including physical activity, sociodemographic factors and even the level of awareness and knowledge need to be considered as they might influence the state of respiratory health. In conclusion, this study shows that exposure to respirable dust in individuals increases the risk of lung function deterioration by the development of respiratory symptoms, besides reduced lung function.

Disclosure statement: The authors declared no conflict of interest.

1. Jaiswal, N., Work related musculoskeletal disorders among construction workers of India. Res. J. Family Commun. Consum. Sci., 2016, 4(2), 1-5.

2. Purani, R. and Shah, N., Prevalence of respiratory symptoms in construction workers in Gujarat: a cross-sectional survey. Int. J. Med. Public Health, 2019, 9(2), 55-58; doi:10.5530/ijmedph. 2019.2.14.

3. McLean, D., Glass, B., Mannetje, A. and Douwes, J., Exposure to respirable crystalline silica in the construction industry-do we have a problem? N. Z. Med. J., 2017, 130(1466), 78-82; https:// assets-global.website-files.com/5e332a62c703f653182faf47/5e 332a62c703f625fc2fd427_McLean-FINAL.pdf

4. Mwaiselage, J., Bråtveit, M., Moen, B. and Mashalla, Y., Cement dust exposure and ventilatory function impairment: an exposureresponse study. J. Occup. Environ. Med., 2004, 46(7), 658-667; doi:10.1097/01.jom.0000131787.02250.79.

5. Ahmad, W., Nisa, S., Nafess, M. and Hussain, R., Assessment of particulate matter (PM10 \& PM2.5) and associated health problems in different areas of cement industry, Hattar, Haripur. J. Sci. Technol. Univ. Peshawar, 2013, 37(2), 7-15.

6. Nij, E. T., Hilhorst, S., Spee, T., Spierings, J., Steffens, F., Lumens, M. and Heederik, D., Dust control measures in the construction industry. Ann. Occup. Hyg., 2003, 47(3), 211-218; doi:10.1093/annhyg/meg023.

7. Lumens, M. E. and Spee, T., Determinants of exposure to respirable quartz dust in the construction industry. Ann. Occup. Hyg., 2001, 45(7), 585-595; doi:10.1016/s0003-4878(01)00025-4.

8. Tavakol, E., Azari, M., Zendehdel, R., Salehpour, S., Khodakrim, S., Nikoo, S. and Saranjam, B., Risk evaluation of construction workers' exposure to silica dust and the possible lung function impairments. Tanaffos, 2017, 16(4), 295-303; PMID: 29849687; PMCID: PMC5971761.

9. Greenberg, M. I., Waksman, J. and Curtis, J., Silicosis: a review. Disease-a-Month, 2007, 53(8), 394-416; doi:10.1016/j.disamonth. 2007.09.020.

10. Mariammal, T., Amutha, A. J. and Sornaraj, R., Work related respiratory symptoms and pulmonary function tests observed among construction and sanitary workers of Thoothukudi. Int. J. PharmTech Res., 2012, 4(3), 1266-1273; https://www.semanticscholar. org/paper/Work-Related-Respiratory-Symptoms-and-Pulmonaryand-Mariammal-Jaisheeba/8f4918e0223a89e7b8c9aadfafb18d725$4 \mathrm{~b} 24 \mathrm{~d} 25$

11. Scarselli, A., Binazzi, A. and Marinaccio, A., Occupational exposure to crystalline silica: estimating the number of workers potentially at high risk in Italy. Am. J. Ind. Med., 2008, 51(12), 941-949; doi:10.1002/ajim.20619.

12. Dement, J. M., Welch, L., Bingham, E., Cameron, B., Rice, C., Quinn, P. and Ringen, K., Surveillance of respiratory diseases among construction and trade workers at Department of Energy nuclear sites. Am. J. Ind. Med., 2003, 43(6), 559-573; doi:10.1002/ajim.10226.

13. Dement, J., Welch, L., Ringen, K., Quinn, P., Chen, A. and Haas, S., A case-control study of airways obstruction among construction workers. Am. J. Ind. Med., 2015, 58(10), 1083-1097; doi:10.1002/ajim.22495.

14. Kasper, D. L., Braunwald, E., Fauci, A. S., Hauser, S. L., Longo, D. L. and Jameson, J. L., Environmental lung diseases. In Harrison's Principles of Internal Medicine, McGraw-Hill, New York, USA, 2008, vol. 2, 16th edn, pp. 1521-1527.

15. Wagner, N. L., Beckett, W. S. and Steinberg, R., Using spirometry results in occupational medicine and research. Common errors and good practice in statistical analysis and reporting. Indian J. Occup. Environ. Med., 2006, 10(1), 5-10; doi:10.4103/0019-5278.22888.

16. Al-Neaimi, Y. I., Gomes, J. and Lloyd, O. L., Respiratory illnesses and ventilatory function among workers at a cement factory in a rapidly developing country. Occup. Med., 2001, 51(6), 367-373; doi:10.1093/occmed/51.6.367.

17. Noor, H., Yap, C. L., Zulkepli, O. and Faridah, M., Effect of exposure to dust on lung function of cement factory workers. Med. J. Malays., 2000, 55(1), 51-57.

18. Chisholm, J., Respirable dust and respirable silica concentrations from construction activities. Indoor Built Environ., 1999, 8(2), 94-106; doi:10.1177/1420326x9900800204.

19. Kamaludin, N. H., Razlan, N. R. A. and Jalaludin, J., Association between respirable dust exposure and respiratory health among cement workers. Malays. J. Med. Health Sci., 2018, 14(SP2), 
78-86; https://medic.upm.edu.my/upload/dokumen/2018120408594611 MJMHS SP Nov 2018.pdf

20. Dehghan, F., Mohammadi, S., Sadeghi, Z. and Attarchi, M., Respiratory complaints and spirometric parameters in tile and ceramic factory workers. Tanaffos, 2009, 8(4), 19-25; http://www. tanaffosjournal.ir/en/archive.php?1rid=293

21. Boskabady, M. H., Rezaiyan, M. K., Navabi, I., Shafiei, S. and Arab, S. S., Work-related respiratory symptoms and pulmonary function tests in northeast Iranian (the city of Mashhad) carpenters. Clinics, 2010, 65(10), 1003-1007; doi:10.1590/s180759322010001000013.

22. Ahmed, A. H., Bilal, I. E. and Merghani, T. H., Effects of exposure to flour dust on respiratory symptoms and lung function of bakery workers. Sudanese J. Public. Health, 2009, 4(1), 210-213; file:///C:/Users/User/Downloads/Paper1.pdf

23. Milanowski, J. et al., Work-related symptoms among furniture factory workers in Lublin region (eastern Poland). Ann. Agric. Environ. Med., 2002, 9(1), 99-103; https://pubmed.ncbi.nlm.nih.gov/ $12088405 /$

24. Neghab, M. and Choobineh, A., Work-related respiratory symptoms and ventilatory disorders among employees of a cement industry in Shiraz, Iran. J. Occup. Health, 2007, 49(4), 273-278; doi: $10.1539 /$ joh. 49.273

25. Ahmed, H. O. and Abdullah, A. A., Dust exposure and respiratory symptoms among cement factory workers in the United Arab Emirates. Ind. Health, 2012, 50(3), 214-222; doi:10.2486/ indhealth.ms 1320 .

26. Park, K., Occupational health. In Park's Textbook of Preventive and Social Medicine, M/s Banarsidas Bhanot, Jabalpur, 2007, 18th edn, pp. 608-610.

27. Karjalainen, A., Martikainen, R., Klaukka, T., Saarinen, K. and Uitti, J., Risk of asthma among Finish patients with occupational rhinitis. Chest, 2003, 123(1), 283-288; doi:10.1378/chest.123. 1.283 .

28. Kakooei, H., Gholami, A., Ghasemkhani, M., Hosseini, M., Panahi, D. and Pouryaghoub, G., Dust exposure and respiratory health effects in cement production. Acta Med. Iran, 2012, 50(2), $122-126$.
29. Ulvestad, B., Lund, M. B., Bakke, B., Djupesland, P. G., Kongerud, J. and Boe, J., Gas and dust exposure in underground construction is associated with signs of airway inflammation. Eur. Respir. J., 2001, 17(3), 416-421; doi:10.1183/09031936.01. 17304160.

30. Johncy, S. S., Ajay, K. T. G., Dhanyakumar, N., Prabhu, R. T. and Samuel, V., Dust Exposure and lung function impairment in construction workers. J. Physiol. Biomed. Sci., 2011, 24(1), 9-13; http://www.j-pbs.org/pdf/241/24(1)_09Johncy.pdf

31. Poornajaf, A., Kakooei, H., Hosseini, M., Ferasati, F. and Kakaei, $\mathrm{H}$., The effect of cement dust on the lung function in a cement factory, Iran. Int. J. Occup. Hyg., 2010, 2(2), 74-78; https://ijoh. tums.ac.ir/index.php/ijoh/article/view/22

32. Nordby, K. C. et al., Exposure to thoracic dust, airway symptoms and lung function in cement production workers. Eur. Resp. J., 2011, 38, 1278-1286; doi:10.1183/09031936.00007711.

33. Ostrowski, S. and Barud, W., Factors influencing lung function: are the predicted values for spirometry reliable enough? $J$. Physiol. Pharmacol., 2006, 57, 263-271; PMID: 17072054.

34. Green, D. A., McAlphine, G., Semple, S., Cowie, H. and Seaton, A., Mineral dust exposure in young Indian adults: an effect on lung growth. Occup. Environ. Med., 2008, 65, 306-310.

35. Yang, C. Y., Huang, C. C., Chiu, H. F., Chiu, J. F., Lan, S. J. and Ko, Y. C., Effect of occupational dust exposure on the respiratory health of Portland cement workers. J. Toxicol. Environ. Health, 1996, 49(6), 581-588; PMID: 8977625.

ACKNOWLEDGMENTS. We thank all the workers for their cooperation, and laboratory assistants of Environmental Health and Industrial Safety Program at Universiti Kebangsaan Malaysia for technical support. Funding for this study was provided by a research grant (GUP-2018-062) from Universiti Kebangsaan Malaysia (UKM).

Received 14 September 2020; accepted 23 September 2020

doi: $10.18520 / \mathrm{cs} / \mathrm{v} 119 / \mathrm{i} 11 / 1789-1796$ 